\title{
Interesse e aprimoramento no diagnóstico do desgaste dentário erosivo
}

\section{RESUMO}

Apesar de sua alta prevalência na população e grandes avanços nos estudos cientificos sobre desgaste dentário erosivo (DDE), observa-se que essa condição ainda não é de amplo conhecimento a população e muitas vezes não é diagnosticada pelos cirurgiões-dentistas. Este estudo foi dividido em dois artigos, o primeiro teve como objetivo caracterizar o interesse dos usuários do Google em informações sobre o desgaste dentário eroviso em diferentes países ao longo do tempo. Foi realizado um estudo longitudinal reprospectivo que anilisou os dados computacionais relacionados ao DDE gerados a partir da atividade de usuários do Google de diferentes países e períodos de tempo (de 01/01/2004 a 03/06/2019, para a análise quantitativa e análise quantitativa, e de 01/01/2004 a 31/12/2010 e de 01/01/2011 a 03/06/2019) coletados pela aplicação da ferramenta Google Trends. Erosion-Topic foi usado como estratégia de busca na categoria de Oral \& Dental. As tendências e os interesses preditivos de 12 meses dos usuários foram analisados por modelos de previsão ARIMA. As consultas mais populares empregadas para usuários do Google foram determinadas para análise qualitativa. Valores de $p<0,05$ foram considerados significativos. Apenas 27 países apresentaram dados de volume suficientes para análise quantitativa, entretanto a análise heurística das curvas não determinou tendências claras para nenhum país deste estudo. Em 15 países foram observadas tendências crescentes comparando as médias dos valores preditivos de RSV com aqueles dos últimos 12 meses coletados. O termo mais pesquisado entre todos os países estudados foi "Erosão", alguns termos eram relacionados a opções de tratamento geral. Concluiuse que os níveis de interesse dos usuários do Google em relação ao DDE se mantiveram baixos e estáveis em todos os países ao longo dos anos, o que pode estar associado a uma contínua falta de conhecimento dessa condição entre leigos e profissionais da odontologia. Com o intuito de melhorar as habilidades de diagnóstico para DDE dos futuros profissionais da odontologia, o segundo artigo teve como objetivo desenvolver, implementar e avaliar o treinamento teórico-prático utilizando metodologias ativas no desenvolvimento de competências de alunos de graduação para o diagnóstico de DDE quando comparado ao método tradicional de ensino baseado em aulas teóricas. Foi realizado um estudo randomizado controlado 
envolvendo dois grupos paralelos: grupo controle $(n=22)$, com aprendizagem embasada somente no conteúdo teórico (aula teórica de 60 minutos) e grupo teste (n =24), aprendizagem por atividade teórico-prática mediada por monitores/ tutores (aula teórica de $60 \mathrm{~min}$ e $90 \mathrm{~min}$ de treinamento prático em laboratório). A aula teórica abordou os conceitos atuais de DDE, sua etiologia, seu diagnóstico (clínico + anamnese), índice utilizado (BEWE), prevenção e tratamento minimamente invasivo. O treinamento prático incluiu exercícios e discussões baseadas no diagnóstico usando pontuações BEWE de um acervo de imagens clínicas e dentes extraídos com ausência e vários níveis de DDE. Para avaliar a eficácia dos métodos de ensinoaprendizagem, foram aplicados um questionário teórico de múltipla escolha e uma avaliação prática com imagens e dentes extraídos. O resultado foi obtido a partir do número de respostas corretas nos testes. Os grupos foram comparados por MannWhitney (conhecimento teórico) e testes T (habilidade prática em diagnóstico) ( $p$ $<0,05)$. Não houve diferença significativa entre os grupos quanto ao percentual de acertos na avaliação teórica. O grupo teste apresentou maior capacidade de diagnosticar lesões DDE e seu índice BEWE correspondente, em comparação ao grupo controle nos testes práticos. Portanto, a atividade prática associada a aulas teóricas pode ser uma estratégia promissora para aprimorar o desenvolvimento de habilidades de alunos de graduação no diagnóstico de DDE.

Palavras-chave: Desgaste dentário; Erosão dentária; Métodos de ensino Conhecimento; Google Trends 